\title{
Doutora Honoris Causa Carolina Martuscelli Bori (1924-2004)
}

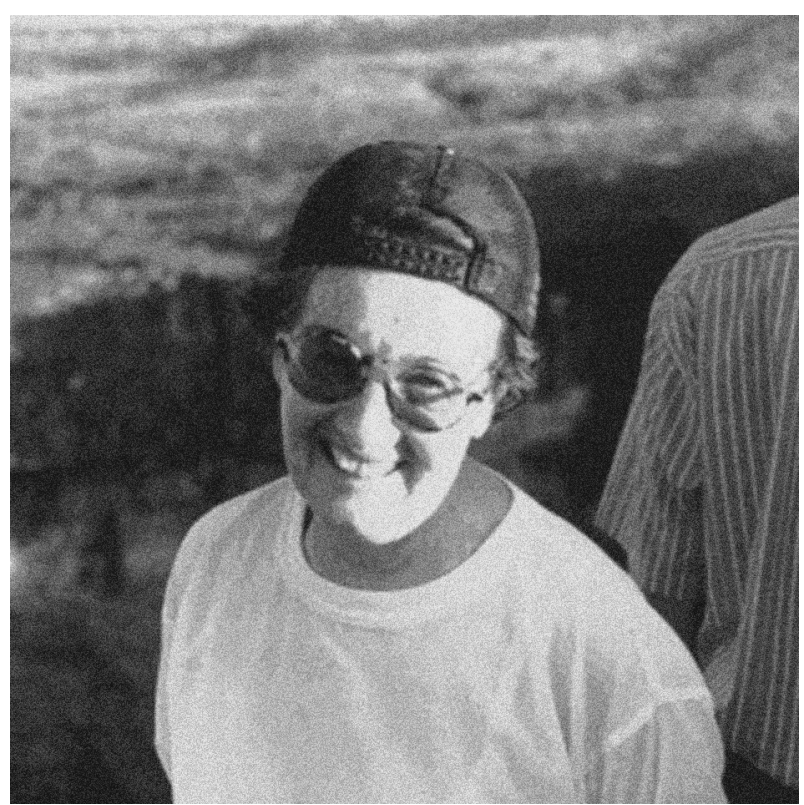

Figura 1. Professora Carolina Martuscelli Bori, Doutora Honoris Causa, in memorian.

Fonte: http://www.scielo.br/img/fbpe/pusp/v9n1/image918.jpg

\section{Carolina Martuscelli Bori: Sob o Olhar de um Lattes a Ser Interpretado \\ Maria Ângela Guimarães Feitosa Universidade de Brasília}

O honroso convite da Reitoria da Universidade de Brasília para que eu fizesse a apresentação de Carolina Martuscelli Bori na cerimônia em que foi agraciada com o título de Doutor Honoris Causa em outubro de 2000 deveu-se a dois fatos: esta cerimônia havia sido integrada à programação da XXX Reunião Anual de Psicologia, da Sociedade Brasileira de Psicologia e, dos professores do Instituto de Psicologia, eu era a que mais recentemente havia trabalhado com Carolina, na comissão de especialistas em Psicologia, junto à Secretaria de Ensino Superior do Ministério da Educação. A tarefa solicitada pelo professor Lauro Morhy era aparentemente de fácil realização porque, por ocasião da "expulsória" de Carolina da Universidade de São Paulo, Maria Amélia Matos havia lhe presenteado, com a organização de um número especial de Psicologia USP, integralmente dedicado a ela, reunindo 51 depoimentos de pessoas com as quais ela havia convivido profissionalmente e que eram partícipes de algum dos vários aspectos de sua riquíssima vida pública. A qualidade do trabalho editorial de Maria Amélia, que cuidou que o material fosse apresentado e organizado em seções, cada uma delas prefaciada, sugestivamente intitulada e ainda dividida em subseções, aliada ao carinho expresso nos diferentes textos, rapidamente tornaram este fascículo material de referência. Mas a envergadura da carreira de Carolina tornou difícil respeitar o limite de 10 minutos de apresentação oral, como solicitava o Cerimonial, para sintetizar as razões que justificavam a homenagem (Feitosa, 2005).

O falecimento de Carolina em outubro de 2004 levou vários veículos a publicarem, nos meses subseqüentes, novos registros de aspectos importantes de sua vida, escritos por pessoas que haviam convivido com ela e que agora recordavam e se despediam. Escrever sobre Carolina tornou-se então uma tarefa de responsabilidade, em respeito a esses dois grupos de preciosos depoimentos, alguns dos quais cito ao longo deste pequeno texto, como forma de convidar o leitor a entrar em contato direto e abrangente com esses materiais. Quando Psicologia: Teoria e Pesquisa me convidou a fazer um registro sobre Carolina, como parte de um número especial em que, ao comemorar os 40 anos de Psicologia na UnB e os 20 anos de Psicologia: Teoria e Pesquisa, o Instituto de Psicologia agradecia a pessoas que haviam marcado sua identidade, perguntei-me como poderia insinuar um olhar. Resolvi, como sugere Maria do Carmo Guedes (2005), escolher um foco, e fui buscá-lo no Currículo Lattes de Carolina, aparentemente apenas para confirmar a avaliação de vários - de que o registro burocrático de seu currículo não expressa sua produção intelectual.

É de conhecimento amplo que orientar alunos era uma atividade que Carolina valorizava e realizava com uma competência extraordinária. Seu Lattes, no entanto, registra 
sua participação em apenas 11 bancas de dissertação de mestrado, quatro de teses de doutorado e seis de qualificação de doutorado, muito distante dos mais de 100 trabalhos orientados. De acordo com classificação de Ana Maria Carvalho, Maria Amélia Matos, Eda Tassara, Maria Ignez Rocha e Silva e Deisy das Graças de Souza (1998) cerca de trinta por cento dessas orientações versam sobre análise de contingências, a temática mais representada. Devemos a Nivaldo Nale (1998) o preenchimento de parte importante da lacuna de identificar esta atividade, quando, ao relatar o papel de Carolina na pesquisa sobre programação de ensino no Brasil, resgata o registro de 31 dissertações e teses orientadas sobre esta temática, excluída uma única superposição com o registro do Lattes. Neste estudo Nivaldo aponta um aspecto inovador da contribuição de Carolina para o sistema personalizado de ensino:

Carolina transmitiu uma concepção até hoje não muito bem compreendida até mesmo por muitos pesquisadores que trabalham com Análise do Comportamento: a idéia de que a escolha dos comportamentos relevantes para serem propostos como objetivo de ensino é a primeira e fundamental tarefa ao se preparar um curso. (p. 277, o grifo meu corresponde ao itálico do autor no original).

A inspeção do Lattes de Carolina traz mais uma perplexidade - o reduzido número de trabalhos plenos. Uma explicação é enfaticamente disponibilizada: Carolina não aceitava ser co-autora das publicações oriundas de teses e dissertações por ela orientadas, argumentando que esses eram trabalhos dos alunos, como lembrado tanto por Deisy como por Gerson Yukio Tomanari, em 2005. Uma segunda explicação é que Carolina se preocupava com a tradição da Psicologia excessivamente pautada por trabalhos teóricos e especulativos, e insistia que o avanço da Psicologia como ciência precisava ser fortalecido a partir de uma sólida base empírica, preferencialmente experimental. Pautava então seu comportamento de escritora por esta visão sobre como avançar a Psicologia. Uma terceira explicação está no cuidado lapidar com a palavra escrita e falada, que não lhe dava o direito de palavras irrefletidas ou desnecessárias.

Qual o efetivo significado da única estrela existente no currículo, a qual deve expressar, conforme instrução do CNPq, a identificação de trabalhos que o próprio autor considera mais importantes? É um trabalho de 1969, inserido na categoria de Livros publicados/organizados ou edições, com o título de "Famílias de categorias baixa e média de status social de centros urbanos: caracterização das relações formais e informais dos membros e do papel social dos cônjuges", que se verifica estar associado a sua tese de livre docência defendida junto à Universidade de São Paulo. Este trabalho representa aquilo que Maria Amélia Matos e Ana Maria Carvalho (1998) resumem como a característica da natureza da atuação de Carolina: militância. $\mathrm{O}$ contexto específico em que esta livre docência ocorreu nos é resgatado por Walter Hugo Cunha (1998), quando nos explica que Carolina foi fortemente pressionada a apressar sua Livre Docência, porque era muito importante que o recém criado Departamento de Psicologia Experimental, com poucos professores titulados e portanto com pouco espaço político, tivesse um Livre Docente.
Mas este trabalho tinha um contexto científico e social antecedente narrado por Carlos Caroso (2004), o qual relata as atividades do antropólogo Carlo Castaldi no Brasil de 1953 a 1955, coletando material para sua tese de Doutorado. Descobrimos que é desta época a colaboração entre Carolina e Maria Isaura Pereira de Queiroz, depois retomada em atividades que ambas mantinham junto à SBPC, conforme esclarecido por esta última (1998). Data também dessa época a colaboração com Eunice Ribeiro Durham, depois retomada de forma intensa no Núcleo de Pesquisa sobre o Ensino Superior da USP, o NUPES. Carolina, Eunice e Maria Isaura se dedicaram a aspectos complementares de fenômenos sociais relacionados a crenças religiosas, em diferentes locais do país. Desse esforço de pesquisa não resultou a tese de Casaldi (inacabada), mas o livro "Mobilidade e Trabalho: Um estudo na cidade de São Paulo", tendo Bertram Hutchinson como primeiro autor. Em sua revisão do livro, Joseph A Kahl (1960) avalia que este havia sido provavelmente o maior e mais sofisticado projeto em sociologia empírica conduzido até então na América Latina e explica que a pesquisa, contratada pela UNESCO e apoiada pelo Ministério da Educação por meio do Centro Brasileiro de Pesquisas Educacionais, tinha como objetivo a identificação de problemas educacionais por meio da compreensão da estrutura social contemporânea.

Se formos buscar no INEP registros de suas atividades mais recentes, encontramos como último trabalho publicado com participação de Carolina, sob os auspícios deste órgão do MEC, "Equidade e Heterogeneidade no Ensino Superior Brasileiro" (2000), elaborado sob supervisão geral de Carolina e Eunice, a partir de pesquisa desenvolvida no NUPES. Neste trabalho identifica-se a preocupação com temáticas como a educação dos estudantes de famílias de baixa renda, as desigualdades regionais no país, o papel da cor no nível de escolaridade dos jovens, a clarificação do papel social que a universidade pública vem exercendo, assuntos sobre os quais ambas já acumulavam estudos. Este trabalho não está registrado no Lattes de Carolina; tampouco está registrada sua colaboração para "Higher Education in Developing Countries. Peril and Promise", um trabalho da Task Force on Higher Education and Society, do BIRD (2000). Interpreto que lhe foi suficiente registrar a origem de sua preocupação com as condições sociais em que a educação ocorre.

A militância enfatizada por Maria Amélia e Ana Maria assume várias formas, sempre veementes, mas comedidas e articuladas. Mais uma vez o Lattes apenas sugere. Carolina ajudou a criar a Associação dos Docentes da Universidade de São Paulo (ADUSP, 2004), lutou pela liberdade de expressão, pela popularização da ciência, pelo ensino público de qualidade, pela defesa da Universidade pública, em momentos em que esta estava ameaçada, como ilustrado no manifesto "A importância da universidade pública" assinado por Alfredo Bosi (2000). Por estas causas usou de várias armas, das quais relato uma que acompanhei mais de perto. Estávamos, a comissão de especialista, trabalhando no Ministério da Educação e Carolina chegou um pouco mais tarde do que o habitual. Entrou na sala com um sorriso discreto e carregando dois estojos, um pequeno e outro maior, e ao mesmo tempo mostrando perplexidade frente à curiosidade geral dos funcionários do MEC, os quais, melhor informados do que nós, a aguardavam para poder apreciar a comenda 
da Ordem ao Mérito Científico, que ela acabara de receber. Sentou-se e nos explicou, quase se desculpando, que quando inicialmente comunicada da premiação, escreveu uma carta para o Presidente da República, à época Fernando Henrique Cardoso, justificando que as condições precárias do ensino no país a impediam de receber a comenda, mas que acabara concordando em recebê-la face à insistência do presidente... e continuamos trabalhando, pois ela não nos concedia muito tempo para prosa. E sobre premiações, o Lattes nada revela, cúmplice de sua usual simplicidade.

Carolina tinha na imprensa uma aliada, o que ficou patente em seu velório quando um jornalista carinhosamente relata seu papel em orientar os jornalistas sobre como interagir com os dirigentes do país em momentos de fragilidade da democracia. Acreditava na importância do cidadão poder fazer uma apropriação crítica do conhecimento científico e não apenas ser um consumidor de seus produtos. Valorizou o jornalismo científico, como podemos apreciar no irreverente depoimento de Flávio Gomes (2007) ao narrar como obteve seu primeiro emprego, junto à SBPC, para implantar um projeto de divulgação científica iniciado sob a coordenação de João Bosco Jardim de Almeida, inspirado em sua experiência na $\mathrm{BBC}$ em Londres, inicialmente na Rádio Cultura como "Encontro com a Ciência", e depois na Rádio USP como "Tome Ciência". Desta experiência Gomes escreve algo que fortalece inúmeros depoimentos colhidos por Maria do Carmo em 2004:

Uma dama, peso pesado da comunidade científica brasileira, que nos tratava como iguais, como se fôssemos importantes na sua cruzada pela divulgação da ciência pelas ondas do rádio. Acho que nunca fomos, mas talvez fôssemos, sei lá. Sempre achei os cientistas uns sonhadores, por isso eles são melhores do que a maioria das pessoas, sonham"

\section{Súmula de Currículo}

Carolina Martuscelli Bori (1924-2004) formou-se em Pedagogia pela Faculdade de Filosofia, Ciências e Letras da Universidade de São Paulo em 1947. Concluiu seu mestrado em 1952 sob a orientação de Tamara Dembo, na New School for Social Research em Nova York, onde se aprofundou na teoria de campo de Kurt Lewin. Fez o Doutorado na Universidade de São Paulo, sob a orientação de Anita Cabral, e em 1954 defendeu tese sobre a teoria da motivação de Lewin. Entrou em contato com a obra de Skinner em 1948, e intensificou seu contato com o behaviorismo com a primeira vinda de Fred Keller ao Brasil em 1961, evento importante na sua identificação teórica com a Análise do Comportamento. Em 1969 defendeu sua tese de Livre Docência sobre "Famílias de categorias baixa e média de status social de centros urbanos: caracterização das relações formais e informais dos membros e do papel social dos cônjuges".

Teve papel importante na política científica da área de Psicologia. Foi presidente da Associação Brasileira de Psicologia, de 1954 a 1955 e novamente de 1963 a 1965, e da Sociedade de Psicologia de São Paulo de 1960 a 1961. Teve participação central na regulamentação da profissão de psicólogo no país e na concepção do decreto lei que determina o currículo mínimo para a formação em Psicologia em 1962 e, na década de 1990, quando o Ministério da Educação determina que a formação de graduação no país passe a ser guiada por diretrizes curriculares, ela exerceu papel central no estabelecimento dessas diretrizes para a Psicologia. Foi ainda presidente da Associação de Modificação do Comportamento, de 1969 a 1973, fundadora e primeira presidente da Associação Nacional de Pesquisa e Pós-graduação em Psicologia, de 1984 a 1986, e primeira Presidente da Sociedade Brasileira de Psicologia, de 1992 a 1993.

Carolina teve participação decisiva na criação de cursos de graduação e de Pós-graduação, disciplinas, laboratórios de Psicologia ou núcleos de pesquisa em várias Universidades públicas brasileiras em cidades como Rio Claro, Brasília, São Paulo, Salvador, São Carlos, Belém, Natal. Em sua primeira incursão na Universidade de Brasília, além de criar um curso de Psicologia alicerçado na produção do conhecimento, assessorou Darcy Ribeiro e, colaborando diretamente com Fred Keller, teve papel decisivo no estabelecimento do método personalizado de ensino para a formação básica nos diferentes cursos de graduação desta Universidade. Retornou a Brasília em 1992 como membro do Conselho Diretor da Fundação Universidade de Brasília, colaboração só encerrada com seu falecimento. Na Universidade de São Paulo, em 1968, ajudou a criar e estruturar o Departamento de Psicologia Social e Experimental do Instituto de Psicologia. Junto com Walter Hugo Cunha, idealizou e implantou o curso de pós-graduação em Psicologia Experimental daquele Instituto, do qual foi coordenadora por 15 anos. No Instituto de Psicologia da USP, sua casa até o fim da vida, passou a ter como colaboradora Maria Amélia Matos, interlocutora privilegiada de indescritíveis diálogos sobre análise do comportamento.

Contribuiu para o estabelecimento do conhecimento empírico necessário para o desenvolvimento de políticas educacionais em sucessivas colaborações com o Ministério da Educação, por meio do desenvolvimento de procedimentos de avaliação de cursos, de trabalhos de campo sobre aspectos da realidade educacional e social, e de estudos acerca do jovem e de sua família, uma atividade iniciada na década de 1950 e consolidada junto ao Núcleo de Pesquisas sobre o Ensino Superior da USP, como sua Diretora Científica, onde teve a colaboração estreita de Eunice Durham.

Teve atuação destacada na política científica, principalmente por meio da Sociedade Brasileira para o Progresso da Ciência. Tendo formalmente iniciado sua participação na SBPC em 1969, na função de Conselheira, assumiu várias funções nesta Sociedade, chegando a Presidente de 1985 a 1989, e finalmente a Presidente de Honra, desde 1989. Nessas funções, e em outras que também exerceu, angariou parceiros incondicionais, como Crodowaldo Pavan, e foi uma incansável defensora da democracia e dos direitos humanos.

A amplitude e o impacto de vários aspectos da carreira de Carolina foram publicamente reconhecidos, de muitas formas. Guilherme Ary Plonski e Rochelle G. Saidel (2001) incluem-na num seleto grupo de cinco mulheres, como um exemplo de mulher brasileira pioneira na ciência. Recebeu os títulos de Professora Emérita pela Universidade de São Paulo em 1994, e de Doutora Honoris Causa, pela Universidade de Brasília em 2000, e pela Universidade Federal de São Carlos em 2003. Junto com Anísio Teixeira, em 1987 foi homenageada pela SBPC. A American Psychological Asso- 
ciation em 1999 concedeu-lhe o Fred S. Keller Behavioral Education Award, em reconhecimento a sua contribuição para o ensino de Psicologia. Em 2001 a Society for the Advancement of Behavior Analysis premia-lhe pela disseminação internacional da Análise do Comportamento. Por duas vezes o governo brasileiro concede-lhe a Ordem do Mérito Científico, sendo em 1998 admitida como Comendador e em 2005, post mortem, como Grã-Cruz, na qualidade de personalidade nacional.

\section{Referências}

ADUSP (2004). Carolina Bori: professora, pesquisadora, guerreira. Informativo ADUSP, no. 173, de 4 de novembro de 2004. Acessado em http://www.adusp.org.br.

Bori, C. M., Durham, E. R. (Superv. Geral), Sampaio, H. (Coord.), Limongi, F. \& Torres, H. (2000). Eqüidade e heterogeneidade na ensino superior brasileiro. Brasília: Instituto Nacional de Estudos e Pesquisas Educacionais. Acessado em http://www. inep.gob.br/download/cibec/2000/titulos_avulsos/miolo_ equidade.pdf.

Bosi, A. (2000). A importância da universidade pública. Ciência Hoje, 28 (165), 42-48.

Caroso, C. (2004). Carlo Castaldi: o reencontro de um náufrago com a Antropologia. Apresentação no Colóquio Internacional O Projeto UNESCO no Brasil: Uma volta crítica ao campo 50 anos depois", realizado na Universidade Federal da Bahia, Salvador, de 12 a 14 de janeiro de 2004. Acesssado em http://www.ceao. ufba.br/unesco/02paper-Caroso.htm.

Carvalho, A., Matos, M. A., Tassara, E. T., Rocha e Silva, M. I. \& Souza, D. G. (1998). Carolina Bori, Psicologia e Ciência no Brasil. Psicologia USP, 9(1), 25-30.

Cunha, W. H, A. (1998). Carolina Martuscelli Bori e a Psicologia na USP. Psicologia USP, 9(1), 49-60.
Feitosa, M. A. G. (2005). Carolina Bori recebe o título de Doutora Honoris Causa pela Universidade de Brasília. Revista Brasileira de Análise do Comportamento, 1(2), 263-267.

Gomes, F. (2007). Ecos de mim mesmo. Acessado em 12/07/2007 em http://z001.ig.com.br/ig/58/14/913038/blig dogomes/2007_ $02 \mathrm{htm}$.

Guedes, M. C. (2004). Memorável Carolina Martuscelli Bori (19242004). Memorandum, 7, 189-195. Acessado em http://www. fafich.ufmg.br/ memorandum/artigos07/guedes01.htm.

Guedes, M. C. (2005). Relembrando Carolina Bori. Paidéia - Cadernos de Psicologia e Educação, 15. Acessado em http:// sites.ffclrp.usp.br/paideia/artigos/30/02.htm.

Kahl, J. (1960). Book Review. The American Journal of Sociology, 66 (3), 303-305.

Matos, M. A. \& Carvalho, A. M. A. (1998). Carolina Martuscelli Bori: uma cientista brasileira. Psicologia: Reflexão e Crítica, 11(2), 411-420.

Nale, N. (1998). Programação de ensino no Brasil: O papel de Carolina Bori. Psicologia USP, 9 (1), 275-301.

Plonski, G. A. \& Saidel, R. G. (2001). Gender, Science and Technology in Brazil. Minerva, 39, 217-238.

Queiroz, M. I. P. (1998). Uma cientista ímpar: Carolina Martuscelli Bori. Psicologia USP, 9(1), 35-37.

Souza, D. G. (2005). Saudades de Carolina. Boletim Contexto (ABPMC), No. 30. Acessado em http://www.abpmc.org.br/ boletim/carolina_1.htm.

The Task Force on Higher Education and Society (2000). Higher Education in Developing Countries. Peril and Promise. Washington, D.C.: The International Bank for Reconstruction and Development / The World Bank.

Tomanari, G. Y. (2005). Pioneirismo na ciência e na psicologia: Carolina Martuscelli Bori (1924-2004). Boletim de Psicologia, LV (123), 241-246. 